\title{
ANÁLISE DA OCORRÊNCIA DE ESTRESSE ENTRE ESTUDANTES DE ENFERMAGEM
}

Maria da Conceição Coelho Brito ${ }^{1}$

Renara Maria Bandeira Vieira Araújo ${ }^{2}$

Maria Socorro de Araújo Dias ${ }^{2}$

Lielma Carla Chagas da Silva ${ }^{2}$

Paloma de Vasconcelos Rodrigues ${ }^{2}$

Marina Pereira Moita ${ }^{2}$

\author{
https://orcid.org/0000-0002-3484-9876 \\ https://orcid.org/0000-0002-8034-3016 \\ https://orcid.org/0000-0002-7813-547X \\ https://orcid.org/0000-0002-2688-9309 \\ https://orcid.org/0000-0003-0066-1485 \\ https://orcid.org/0000-0002-1920-480X
}

Objetivo: analisar a ocorrência de estresse com discentes de enfermagem inseridos em vivências práticas na modalidade de internato em uma Escola de Enfermagem. Metodologia: Estudo exploratório-descritivo, quantitativo, com 96 internos de enfermagem. Utilizou-se para coleta: questionário sociodemográfico e acadêmico, e instrumento para averiguação de ocorrência de estresse. Dados tabulados no software Epi Info e apresentados em tabelas. Resultados: O resultado prevalente sobre a ocorrência de estresse foi "sentir-se pouco estressado com as situações propostas", 36 (37,5\%) dos discentes. A presença de estresse no cotidiano é um dado preocupante, visto que pode inferir no exercício da profissão ou ainda na vida acadêmica. Conclusão: $O$ estudo permitiu uma reflexão sobre as dificuldades encontradas no ambiente universitário e que sujeitam os discentes a situações estressoras, reconhecendo a necessidade de um melhor cuidado de si e do outro.

Descritores: Estudantes de Enfermagem; Saúde Mental; Internato não médico; Educação Superior.

\section{ANALYSIS OF THE OCCURRENCE OF STRESS AMONG NURSING STUDENTS}

Objective: to analyze the occurrence of stress with nursing students enrolled in practical experiences in the modality of boarding school in a Nursing School. Methodology: Exploratory-descriptive, quantitative study with 96 nursing interns. It was used to collect: sociodemographic and academic questionnaire, and instrument to investigate the occurrence of stress. Data tabulated in the Epi Info software and presented in tables. Results: The prevalent result on the occurrence of stress was "feeling little stressed with the proposed situations", 36 (37.5\%) of the students. The presence of daily stress is a cause for concern, since it can be inferred in the exercise of the profession or even in the academic life. Conclusion: The study allowed a reflection on the difficulties found in the university environment and which subjects students to stressful situations, recognizing the need for better care of themselves and the other.

Descriptors: Nursing students; Mental Health; Internship nonmedical; Education Higher.

\section{ANÁLISIS DE LA OCURRENCIA DE ESTRÉS ENTRE LOS ESTUDIANTES DE ENFERMERÍA}

Objetivo: analizar la ocurrencia de estrés con discentes de enfermería insertados en vivencias prácticas en la modalidad de internado en una Escuela de Enfermería. Metodología: Estudio exploratorio-descriptivo, cuantitativo, con 96 internos de enfermería. Se utilizó para colecta: cuestionario sociodemográfico y académico, e instrumento para averiguación de ocurrencia de estrés. Datos tabulados en el software Epi Info y presentados en tablas. Resultados: El resultado prevalente sobre la ocurrencia de estrés fue "sentirse poco estresado con las situaciones propuestas", 36 (37,5\%) de los discentes. La presencia de estrés en el cotidiano es un dato preocupante, ya que puede inferir en el ejercicio de la profesión o aún en la vida académica. Conclusión: El estudio permitió una reflexión sobre las dificultades encontradas en el ambiente universitario y que sujeta a los discentes a situaciones estresantes, reconociendo la necesidad de un mejor cuidado de si y del otro.

Descriptores: Estudiantes de Enfermería; Salud mental; Internado no médico; Educación universitaria.

${ }^{1}$ Universidade Estadual do Ceará (UECE),CE

${ }^{2}$ Universidade Estadual Vale do Acaraú, Sobral, CE

Autor correspondente: Maria da Conceição Coelho Brito - Email: marycey@hotmail.com 


\section{INTRODUÇÃO}

As concepções, exigências e inovações tecnológicas no mercado de trabalho têm provocado a busca por profissionais altamente competentes com vistas ao aumento da produtividade ${ }^{(1)}$. Isso torna o mercado de trabalho mais competitivo e, consequentemente, os indivíduos anseiam qualificações cada vez maiores.

Desse modo, a busca por uma formação universitária se torna ascendente, aspecto que influencia na expansão de vagas ofertadas e ampliação das universidades, democratizando mais o acesso à educação. Informações do Instituto Nacional de Estudos e Pesquisas Educacionais(INEP) apresentam que, em 2010, foram ofertadas 3.120.192 vagas em Instituições de Ensino Superior (IES). No ano de 2017, esse número passou para mais de 10,7 milhões de vagas em cursos de graduação ${ }^{(2)}$.

O exposto tem influência em razão do ambiente acadêmico ser responsável pela construção de conhecimentos e oferta de vivências práticas para formação profissional. Contudo, também pode ser fator desencadeante de estresse, devido momentos de mudança, desenvolvimento, frustração e dúvidas relacionadas ao curso (3), e pelas exigências crescentes impostas pelo mercado de trabalho.

A vivência acadêmica é imprescindivel para o desenvolvimento do futuro profissional. Vários desafios são enfrentados, tanto de ordem pessoal, social e acadêmica, contudo, a principal delas é preparação para o mercado de trabalho ${ }^{(4)}$. O internato de enfermagem é uma etapa fundamental para formação e desenvolvimento de competências para a prática da profissão, porém, há desafios relacionados a sua efetivação em razão da articulação do serviço e a universidade, o que dificulta a avaliação e acompanhamento pedagógico e psicológico ao interno no serviço de saúde ${ }^{(5)}$.

Durante o internato, configurado como uma etapa de alto desempenho, os estudantes tendem a camuflar os sentimentos de estresse vivenciados durante os momentos de prática. Ademais, essa etapa é formada por diversas alterações que ocorrem no âmbito familiar, social e pessoal, em razão do novo meio e da nova rotina, e da necessidade de dedicar seu tempo aos estudos, a integração com novos colegas, profissionais da equipe de saúde, professores e adquirir novos hábitos ${ }^{(6)}$.

Tensão emocional, desgaste físico e psicológico estão presentes no curso da vida dos indivíduos. $O$ estresse na vida universitária vem se tornando cada vez mais evidente. No entanto, há uma restrição de pesquisas internacionais, consequentemente pouca discussão na realidade brasileira, em especial, com estudantes de enfermagem. A discus- são do presente tema tem importância para as ciências do comportamento e repercute na qualidade de vida dos estudantes e futuros profissionais.

Compreende-se que o estresse apresenta relação direta com o processo de adaptação do indivíduo às demandas internas e externas, ocasionando a redução da sua capacidade física e mental, e diminuição da resistência às doenças. E que diante desse fenômeno, pode levar o indivíduo a fase de esgotamento, sendo manifestado por sintomas físicos ou psicológicos, o que pode resultar na vulnerabilidade do organismo a doenças ${ }^{(7)}$. O estudo, então, traz como objetivo analisar a ocorrência de estresse em discentes de enfermagem inseridos em vivências práticas na modalidade de internato em uma Escola de Enfermagem.

\section{METODOLOGIA}

\section{Tipo de estudo}

Estudo exploratório-descritivo, de caráter quantitativo, desenvolvido no ano 2016.

\section{Participantes do estudo}

Os participantes do estudo foram discentes regularmente matriculados nas vivências práticas do internato, contabilizando 97 discentes, sendo 30 do Internato I (Atenção Básica), 36 do Internato II (Atenção Especializada) e 31 no Internato III (Atenção Hospitalar). A intenção do estudo era que a totalidade dos discentes participassem, contudo, $\mathrm{Ol}$ (um) matriculado no Internato I não participou por estar afastado do curso devido tratamento de saúde no periodo da coleta de dados. Assim, o estudo teve como participantes 96 discentes, o que correspondeu a 99,0\% do total.

\section{Local do Estudo}

O estudo foi realizado em uma Escola de Enfermagem brasileira, que conta com três (03) módulos de internatos que acontecem no 8ㅇ, 9ㅇ e 10으 semestres do curso, com inserção nos serviços de atenção básica, especializada e hospitalar, respectivamente.

\section{Coleta de dados}

A coleta de dados ocorreu no período de setembro a outubro de 2016 e utilizou dois instrumentos aplicados presencialmente com os discentes. Um instrumento composto por questionário sociodemográfico e itens de cunho acadêmico ${ }^{(8)}$, e outro para a avaliação da ocorrência de estresse, o instrumento Avaliação de Estresse em Estudantes de Enfermagem - AEEE ${ }^{(9)}$.

O instrumento de AEEE é por 30 itens distribuídos em seis domínios, que são: realização das atividades práticas; 
comunicação profissional; gerenciamento do tempo; ambiente; formação profissional e atividades teóricas. Há uma definição de valores que variam de zero a três de acordo com a escala de Likert, que identifica possíveis situações de estresse vivenciadas pelos discentes. Na escala, o zero está ligado ao fato de os discentes não vivenciarem a situação. A opção um significa que o mesmo não se sente estressado com a situação. Ao optar pelo dois o mesmo afirma sentir-se pouco estressado com a situação. E o número três está relacionado a situações muito estressantes. Com isso, as experiências vivenciadas pelos discentes são classificadas de zero (valor mínimo) a três (valor máximo) ${ }^{(9)}$.

\section{Análise de dados}

Os dados coletados foram tabulados no software Epi Info versão 7 e apresentadas em tabelas para realização de análise e interpretações. Realizaram-se inferências a partir dos resultados e diálogos com a literatura na perspectiva de provocar reflexões sobre situações estressantes com discentes de enfermagem.

\section{Procedimentos éticos}

O estudo foi aprovado por um Comitê de Ética em Pesquisa sob Parecer № 1.590.511/2016. Salienta-se que todos os participantes deram anuência mediante assinatura do Termo de Consentimento Livre e Esclarecido.

\section{RESULTADOS}

Os 96 discentes participantes do estudo estão, assim, distribuidos: 29 (30,2\%) no internato I, 36 (37,5\%) no internato II e 31 (32,3\%) no internato III. Há um predomínio da faixa etária de 20 a 24 anos com 73 (76\%) discentes, sendo predominantemente do sexo feminino, 76 (79,2\%), e dos que referem ser solteiros, sendo $79(82,4 \%)$.

Quanto a possuírem filhos, 84 (87,5\%) participantes afirmam não ter. Sobre a moradia, 49 (51\%) discentes referem morar com a família, 40 (41,7\%) moram com amigos/ colegas e apenas 7 (7,3\%) moram sozinhos. Entre os discentes, 67 (69,8\%) não praticam esportes e 70 (72,9\%) realizam atividades de lazer.

Os dados referentes aos itens de cunho acadêmico expressam que 88 (91,7\%) discentes referem estar satisfeitos com o curso, sendo a maior ocorrência de satisfação no internato II, com 35 (36,5\%) participantes. Quanto à participação em grupos de estudo e pesquisa, 67 (69,9\%) declararam não participar. Verificou-se que 39 (40,6\%) discentes recebem algum tipo de bolsa. A maioria, representada por 71 (74,0\%) discentes, não desenvolve atividades de trabatho, 70 (72,9\%) referiram que não possuem experiência pro- fissional na área da saúde e 86 (89,6\%) relataram não ter outro nivel superior. Em relação a intenção de desistir do curso de enfermagem, 54 (56,3\%) afirmaram já terem pensado.

Da aplicação do instrumento de AEEE, verificaram-se, na Tabela 1, dados significativos para a ocorrência de estresse. No domínio "Realização das atividades práticas", houve prevalência da situação "ter medo de cometer erros durante a assistência ao paciente", expressado por 37 $(38,5 \%)$, sendo essa situação mais manifesta no internato II, com 18 (50\%) discentes.

Tabela 1- Distribuição dos domínios "Realização das atividades práticas", “comunicação profissional" e "gerência do tempo" por internato. Sobral-CE, 2017.

\begin{tabular}{|c|c|c|c|c|c|c|c|}
\hline \multicolumn{8}{|c|}{ Domínio - Realização das Atividades Práticas } \\
\hline \multicolumn{2}{|c|}{ Itens } & $\begin{array}{l}\text { Realizar } \\
\text { procedi- } \\
\text { mentos } \\
\text { assis- } \\
\text { tenciais } \\
\text { de } \\
\text { modo } \\
\text { geral }\end{array}$ & $\begin{array}{l}\text { As novas } \\
\text { situa- } \\
\text { ções que } \\
\text { poderá } \\
\text { viven- } \\
\text { ciar na } \\
\text { prática } \\
\text { clinica }\end{array}$ & $\begin{array}{l}\text { O am- } \\
\text { biente } \\
\text { da uni- } \\
\text { dade } \\
\text { clinica } \\
\text { de es- } \\
\text { tágio }\end{array}$ & $\begin{array}{l}\text { Medo } \\
\text { de co- } \\
\text { meter } \\
\text { erros } \\
\text { duran- } \\
\text { te a } \\
\text { assis- } \\
\text { tência } \\
\text { ao } \\
\text { pa- } \\
\text { ciente }\end{array}$ & $\begin{array}{l}\text { Executar } \\
\text { deter- } \\
\text { minados } \\
\text { procedi- } \\
\text { mentos } \\
\text { assis- } \\
\text { tenciais }\end{array}$ & $\begin{array}{l}\text { Sentir } \\
\text { que } \\
\text { adquiriu } \\
\text { pouco } \\
\text { conhe- } \\
\text { cimento } \\
\text { para } \\
\text { fazer a } \\
\text { prova } \\
\text { prática }\end{array}$ \\
\hline \multicolumn{8}{|c|}{ Internato $I^{*}$} \\
\hline \multirow[t]{2}{*}{0} & $\mathbf{N}$ & 2 & 1 & 2 & 1 & 2 & 1 \\
\hline & $\%$ & 6,9 & 3,4 & 6.9 & 3,4 & 6,9 & 3,4 \\
\hline \multirow[t]{2}{*}{1} & $\mathbf{N}$ & 17 & 11 & 20 & 7 & 15 & 5 \\
\hline & $\%$ & 58,6 & 38 & 69 & 24,1 & 51,7 & 17,2 \\
\hline \multirow[t]{2}{*}{2} & $\mathbf{N}$ & 8 & 10 & 5 & 9 & 7 & 11 \\
\hline & $\%$ & 27,6 & 34,5 & 17,2 & 31 & 24,1 & 38 \\
\hline \multirow[t]{2}{*}{3} & $\mathbf{N}$ & 2 & 7 & 2 & 12 & 5 & 12 \\
\hline & $\%$ & 6,9 & 24,1 & 6,9 & 41,4 & 17,2 & 41,4 \\
\hline \multicolumn{8}{|c|}{ Internato II $^{\star * *}$} \\
\hline \multirow[t]{2}{*}{0} & $\mathbf{N}$ & 0 & 0 & 2 & 0 & 0 & 1 \\
\hline & $\%$ & 0 & 0 & 5,6 & 0 & 0 & 2,8 \\
\hline \multirow[t]{2}{*}{1} & $\mathbf{N}$ & 19 & 14 & 18 & 5 & 14 & 8 \\
\hline & $\%$ & 52,8 & 38,9 & 50 & 13,9 & 38,9 & 22,2 \\
\hline \multirow[t]{2}{*}{2} & $\mathbf{N}$ & 13 & 14 & 9 & 13 & 19 & 11 \\
\hline & $\%$ & 36,1 & 38,9 & 25 & 36,1 & 52,8 & 30,6 \\
\hline \multirow[t]{2}{*}{3} & $\mathbf{N}$ & 4 & 8 & 7 & 18 & 3 & 16 \\
\hline & $\%$ & 11,1 & 22,2 & 19,4 & 50 & 8,3 & 44,4 \\
\hline \multicolumn{8}{|c|}{ Internato III ${ }^{* * *}$} \\
\hline \multirow[t]{2}{*}{0} & $\mathbf{N}$ & 2 & 1 & 2 & 0 & 1 & 3 \\
\hline & $\%$ & 6,4 & 3,2 & 6,5 & 0 & 3,2 & 9,7 \\
\hline \multirow[t]{2}{*}{1} & $\mathbf{N}$ & 18 & 9 & 18 & 6 & 13 & 10 \\
\hline & $\%$ & 58,1 & 29 & 58,1 & 19,4 & 41,9 & 32,3 \\
\hline
\end{tabular}




\begin{tabular}{llllllll}
$\mathbf{2}$ & $\mathbf{N}$ & 7 & 14 & 10 & 18 & 13 & 13 \\
& $\%$ & 22,6 & 45,2 & 32,3 & 58 & 41,9 & 41,9 \\
\hline 3 & $\mathbf{N}$ & 4 & 7 & 1 & 7 & 4 & 5 \\
& $\%$ & 12,9 & 22,6 & 3,2 & 22,6 & 13 & 16,1
\end{tabular}

Dominio - Comunicação Profissional

\begin{tabular}{|c|c|c|c|c|}
\hline Itens & $\begin{array}{l}\text { Comu- } \\
\text { nicação } \\
\text { com os } \\
\text { demais } \\
\text { profissio- } \\
\text { nais da } \\
\text { unidade } \\
\text { de estágio }\end{array}$ & $\begin{array}{l}\text { Comunicação } \\
\text { com os profis- } \\
\text { sionais de outros } \\
\text { setores no local } \\
\text { de serviço }\end{array}$ & $\begin{array}{l}\text { Perce- } \\
\text { ber as } \\
\text { dificul- } \\
\text { dades } \\
\text { que } \\
\text { envol- } \\
\text { vem o } \\
\text { relacio- } \\
\text { namen- } \\
\text { to com } \\
\text { outros } \\
\text { profis- } \\
\text { sionais } \\
\text { da área }\end{array}$ & $\begin{array}{l}\text { Observar atitudes } \\
\text { conflitantes com } \\
\text { outros profissio- } \\
\text { nais }\end{array}$ \\
\hline
\end{tabular}

Internato I*

\begin{tabular}{|llllll|}
\hline $\mathbf{0}$ & $\mathbf{N}$ & 2 & 1 & 2 & 2 \\
& $\%$ & 6,9 & 3,4 & 6,9 & 6,9 \\
\hline $\mathbf{1}$ & $\mathbf{N}$ & 24 & 26 & 13 & 6 \\
& $\%$ & 82,8 & 98,7 & 44,8 & 20,7 \\
\hline $\mathbf{2}$ & $\mathbf{N}$ & 1 & 2 & 11 & 15 \\
& $\%$ & 3,4 & 6,9 & 38 & 51,7 \\
\hline $\mathbf{3}$ & $\mathbf{N}$ & 2 & 0 & 3 & 6 \\
& $\%$ & 6,9 & 0 & 10,3 & 20,7 \\
\hline
\end{tabular}

\begin{tabular}{|c|c|c|c|c|c|}
\hline \multicolumn{6}{|c|}{ Internato $\mathrm{II}^{\star *}$} \\
\hline \multirow[t]{2}{*}{0} & $\mathbf{N}$ & 2 & 1 & 0 & 0 \\
\hline & $\%$ & 5,6 & 2,8 & 0 & 0 \\
\hline \multirow[t]{2}{*}{1} & $\mathbf{N}$ & 21 & 20 & 14 & 10 \\
\hline & $\%$ & 58,3 & 55,5 & 38,9 & 27,8 \\
\hline \multirow[t]{2}{*}{2} & $\mathbf{N}$ & 9 & 14 & 15 & 17 \\
\hline & $\%$ & 25 & 38,9 & 41,7 & 47,2 \\
\hline \multirow[t]{2}{*}{3} & $\mathbf{N}$ & 4 & 1 & 7 & 9 \\
\hline & $\%$ & 11,1 & 2,8 & 19,4 & 25 \\
\hline
\end{tabular}

\begin{tabular}{|c|c|c|c|c|c|}
\hline \multicolumn{6}{|c|}{ Internato III ${ }^{* * *}$} \\
\hline \multirow[t]{2}{*}{0} & $\mathbf{N}$ & 5 & 0 & 2 & 1 \\
\hline & $\%$ & 16,1 & 0 & 6,5 & 3,2 \\
\hline \multirow[t]{2}{*}{1} & $\mathbf{N}$ & 20 & 23 & 13 & 11 \\
\hline & $\%$ & 64,5 & 74,2 & 41,9 & 35,5 \\
\hline \multirow[t]{2}{*}{2} & $\mathbf{N}$ & 6 & 8 & 16 & 13 \\
\hline & $\%$ & 19,4 & 25,8 & 51,6 & 41,9 \\
\hline \multirow[t]{2}{*}{3} & $\mathbf{N}$ & 0 & 0 & 0 & 6 \\
\hline & $\%$ & 0 & 0 & 0 & 19,4 \\
\hline
\end{tabular}

Dominio - Comunicação Profissional

$\begin{array}{llllll} & \text { Estarfora } & \text { Tempo } & & & \text { Faltar } \\ \text { do convi- } & \text { reduzido } & \text { Tempo exigido } & & \text { Faltar } & \text { tempo } \\ & \text { vio social } & \text { para } & \text { pelo professor } & \text { tempo } & \text { para } \\ \text { vitens } & \text { traz sen- } & \text { estar } & \text { para a entrega } & \text { para o } & \text { mo- } \\ & \text { timentos } & \text { com os } & \text { das atividades } & \text { lazer } & \text { mentos } \\ & \text { de soli- } & \text { familia- } & \text { extraclasse } & & \text { des- } \\ \text { dão } & \text { res } & & & \text { canso }\end{array}$

\begin{tabular}{|c|c|c|c|c|c|c|}
\hline \multicolumn{7}{|c|}{ Internato $I^{*}$} \\
\hline \multirow[t]{2}{*}{0} & $\mathbf{N}$ & 3 & 0 & 1 & 0 & 0 \\
\hline & $\%$ & 10,3 & 0 & 3,4 & 0 & 0 \\
\hline \multirow[t]{2}{*}{1} & $\mathbf{N}$ & 8 & 5 & 10 & 4 & 4 \\
\hline & $\%$ & 27,6 & 17,2 & 34,5 & 13,8 & 13,8 \\
\hline \multirow[t]{2}{*}{2} & $\mathbf{N}$ & 13 & 7 & 11 & 7 & 5 \\
\hline & $\%$ & 44,9 & 24,1 & 38 & 24,1 & 17,2 \\
\hline \multirow[t]{2}{*}{3} & $\mathbf{N}$ & 5 & 17 & 7 & 18 & 20 \\
\hline & $\%$ & 17,2 & 28,7 & 24,1 & 62,1 & 69 \\
\hline
\end{tabular}

\begin{tabular}{|c|c|c|c|c|c|c|}
\hline \multicolumn{7}{|c|}{ Internato $\mathrm{II}^{* *}$} \\
\hline \multirow[t]{2}{*}{0} & $\mathbf{N}$ & 3 & 0 & 1 & 2 & 0 \\
\hline & $\%$ & 8,3 & 0 & 2,8 & 5,6 & 0 \\
\hline \multirow[t]{2}{*}{1} & $\mathbf{N}$ & 9 & 5 & 8 & 7 & 5 \\
\hline & $\%$ & 25 & 13,9 & 22,2 & 19,4 & 13,9 \\
\hline \multirow[t]{2}{*}{2} & $\mathbf{N}$ & 10 & 12 & 20 & 14 & 11 \\
\hline & $\%$ & 27,8 & 33,3 & 55,6 & 38,9 & 30,5 \\
\hline \multirow[t]{2}{*}{3} & $\mathbf{N}$ & 14 & 19 & 7 & 13 & 20 \\
\hline & $\%$ & 38,9 & 52,8 & 19,4 & 36,1 & 55,6 \\
\hline
\end{tabular}

\begin{tabular}{|c|c|c|c|c|c|c|}
\hline \multicolumn{7}{|c|}{ Internato III ${ }^{* * *}$} \\
\hline \multirow[t]{2}{*}{0} & $\mathbf{N}$ & 5 & 0 & 1 & 1 & 0 \\
\hline & $\%$ & 16,1 & 0 & 3,2 & 3,2 & 0 \\
\hline \multirow[t]{2}{*}{1} & $\mathbf{N}$ & 11 & 3 & 8 & 10 & 5 \\
\hline & $\%$ & 35,5 & 9,7 & 25,8 & 32,3 & 16,1 \\
\hline \multirow[t]{2}{*}{2} & $\mathbf{N}$ & 11 & 13 & 13 & 12 & 11 \\
\hline & $\%$ & 35,5 & 41,9 & 42 & 38,7 & 35,5 \\
\hline \multirow[t]{2}{*}{3} & $\mathbf{N}$ & 4 & 15 & 9 & 8 & 15 \\
\hline & $\%$ & 12,9 & 48,4 & 29 & 25,8 & 48,4 \\
\hline
\end{tabular}

*Valor percentual calculado considerando o número total de discentes no Internato I (29 participantes);

** Valor percentual calculado considerando o número total de discentes no Internato II (36 participantes);

${ }^{\star * \star}$ Valor percentual calculado considerando o número total de discentes no Internato III (31 participantes.

No domínio "Comunicação Profissional" prevaleceu "observar atitudes conflitantes em outros profissionais", $21(21,9 \%)$ discentes, tendo maior presença no internato II, com 9 (25\%). Já no domínio "Gerenciamento de Tempo", há prevalência da situação "falta de tempo para momentos de descanso", 55 (57,3\%) discentes, sendo que o internato I apresenta maior expressividade desse quesito, 20 (69,0\%).

Na Tabela 2 consta que, no domínio "Ambiente", o item "distância entre a maioria dos campos de estágio e o local de moradia" apresentou 29 (30,2\%) discentes muito estressados com a situação, onde o internato II destacou-se, manifestado por 12 (33,3\%) participantes. 
Tabela 2- Distribuição dos domínios “Ambiente", “Formação Profissional" e "Atividade teórica" por internato. SobralCE, 2017.

\begin{tabular}{|c|c|c|c|c|}
\hline \multicolumn{5}{|c|}{ Dominio - Ambiente } \\
\hline Itens & $\begin{array}{l}\text { Distância en- } \\
\text { tre a faculda- } \\
\text { de e o local } \\
\text { de moradia }\end{array}$ & $\begin{array}{l}\text { Transpor- } \\
\text { te público } \\
\text { utilizado para } \\
\text { chegar à } \\
\text { faculdade }\end{array}$ & $\begin{array}{l}\text { Distância en- } \\
\text { tre a maioria } \\
\text { dos campos } \\
\text { de estágio } \\
\text { e o local de } \\
\text { moradia }\end{array}$ & $\begin{array}{l}\text { Transpor- } \\
\text { te público } \\
\text { utilizado para } \\
\text { chegar ao } \\
\text { estágio }\end{array}$ \\
\hline
\end{tabular}

\begin{tabular}{|llllll|}
\hline \multicolumn{2}{|c|}{ Internato $\mathbf{I}^{*}$} & 13 & 1 & 10 \\
\hline $\mathbf{0}$ & $\mathbf{N}$ & 2 & 44,8 & 6,9 & 34,5 \\
\hline $\mathbf{1}$ & $\mathbf{N}$ & 6,9 & 4 & 8 & 9 \\
\hline $\mathbf{2}$ & $\mathbf{N}$ & 5 & 13,8 & 27,6 & 31 \\
\hline $\mathbf{3}$ & $\mathbf{N}$ & 17,1 & 6 & 8 & 4 \\
\hline & $\%$ & 38 & 20,7 & 27,6 & 13,8 \\
\hline
\end{tabular}

\begin{tabular}{|c|c|c|c|c|c|}
\hline \multicolumn{6}{|c|}{ Internato $\mathrm{II}^{* *}$} \\
\hline \multirow[t]{2}{*}{0} & $\mathbf{N}$ & 4 & 13 & 4 & 12 \\
\hline & $\%$ & 11,1 & 36,1 & 11,1 & 33,3 \\
\hline \multirow[t]{2}{*}{1} & $\mathbf{N}$ & 14 & 9 & 8 & 7 \\
\hline & $\%$ & 38,9 & 25 & 22,2 & 19,4 \\
\hline \multirow[t]{2}{*}{2} & $\mathbf{N}$ & 8 & 5 & 12 & 5 \\
\hline & $\%$ & 22,2 & 13,9 & 33,3 & 13,9 \\
\hline \multirow[t]{2}{*}{3} & $\mathbf{N}$ & 10 & 9 & 12 & 12 \\
\hline & $\%$ & 27,8 & 25 & 33,3 & 33,3 \\
\hline
\end{tabular}

Internato III ***

\begin{tabular}{|llllll|}
\hline $\mathbf{0}$ & $\mathbf{N}$ & 4 & 13 & 3 & 16 \\
& $\%$ & 12,9 & $\times 42$ & 9,7 & 51,6 \\
\hline $\mathbf{1}$ & $\mathbf{N}$ & 16 & 9 & 11 & 5 \\
& $\%$ & 51,6 & 29 & 35,5 & 16,1 \\
\hline $\mathbf{2}$ & $\mathbf{N}$ & 6 & 5 & 11 & 7 \\
\hline $\mathbf{3}$ & $\mathbf{N}$ & 5 & 16,1 & 35,5 & 22,6 \\
\hline & $\%$ & 16,1 & 4 & 6 & 3 \\
\hline
\end{tabular}

Domínio - Formação Profissional

\begin{tabular}{|c|c|c|c|c|c|c|}
\hline Itens & $\begin{array}{l}\text { Ter } \\
\text { preocu- } \\
\text { pação } \\
\text { com o } \\
\text { futuro } \\
\text { profis- } \\
\text { sional }\end{array}$ & $\begin{array}{l}\text { A seme- } \\
\text { lhança } \\
\text { entre as } \\
\text { situa- } \\
\text { ções } \\
\text { que } \\
\text { viven- } \\
\text { cia no } \\
\text { estágio } \\
\text { e aque- } \\
\text { las que } \\
\text { poderá } \\
\text { viven- } \\
\text { ciar na } \\
\text { vida } \\
\text { profis- } \\
\text { sional }\end{array}$ & $\begin{array}{l}\text { Pensar } \\
\text { nas si- } \\
\text { tuações } \\
\text { que } \\
\text { poderá } \\
\text { viven- } \\
\text { ciar } \\
\text { quando } \\
\text { for } \\
\text { enfer- } \\
\text { meiro }\end{array}$ & $\begin{array}{l}\text { Perce- } \\
\text { ber a } \\
\text { respon- } \\
\text { sabi- } \\
\text { lidade } \\
\text { profis- } \\
\text { sional } \\
\text { quando } \\
\text { está } \\
\text { atuan- } \\
\text { do no } \\
\text { campo }\end{array}$ & $\begin{array}{l}\text { Viven- } \\
\text { ciar as } \\
\text { ativi- } \\
\text { dades, } \\
\text { como } \\
\text { enfer- } \\
\text { meiro } \\
\text { em } \\
\text { forma- } \\
\text { ção, no } \\
\text { campo } \\
\text { de está- } \\
\text { gio }\end{array}$ & $\begin{array}{l}\text { Relação } \\
\text { entre o } \\
\text { conhe- } \\
\text { cimento } \\
\text { teórico } \\
\text { adqui- } \\
\text { rido no } \\
\text { curso e } \\
\text { o futuro } \\
\text { desem- } \\
\text { penho } \\
\text { profis- } \\
\text { sional }\end{array}$ \\
\hline
\end{tabular}

\begin{tabular}{|c|c|c|c|c|c|c|c|}
\hline \multicolumn{8}{|c|}{ Internato I* } \\
\hline \multirow[t]{2}{*}{0} & $\mathbf{N}$ & 0 & 1 & 1 & 0 & 1 & 0 \\
\hline & $\%$ & 0 & 3,4 & 34 & 0 & 3,4 & 0 \\
\hline \multirow[t]{2}{*}{1} & $\mathbf{N}$ & 3 & 11 & 7 & 9 & 16 & 7 \\
\hline & $\%$ & 10,3 & 38 & 24,1 & 31 & 55,2 & 24,1 \\
\hline \multirow[t]{2}{*}{2} & $\mathbf{N}$ & 10 & 12 & 10 & 10 & 9 & 9 \\
\hline & $\%$ & 34,5 & 41,4 & 34,5 & 34,5 & 31 & 31 \\
\hline \multirow[t]{2}{*}{3} & $\mathbf{N}$ & 16 & 5 & 11 & 10 & 3 & 13 \\
\hline & $\%$ & 55,2 & 17,2 & 38 & 34,5 & 10,3 & 44,8 \\
\hline
\end{tabular}

\begin{tabular}{|c|c|c|c|c|c|c|c|}
\hline \multicolumn{8}{|c|}{ Internato II ${ }^{* *}$} \\
\hline \multirow[t]{2}{*}{0} & $\mathbf{N}$ & 0 & 0 & 0 & 0 & 0 & 0 \\
\hline & $\%$ & 0 & 0 & 0 & 0 & 0 & 0 \\
\hline \multirow[t]{2}{*}{1} & $\mathbf{N}$ & 4 & 8 & 6 & 7 & 13 & 7 \\
\hline & $\%$ & 11,1 & 22,2 & 16,7 & 19,4 & 36,1 & 19,4 \\
\hline \multirow[t]{2}{*}{2} & $\mathbf{N}$ & 17 & 20 & 17 & 19 & 18 & 22 \\
\hline & $\%$ & 47,2 & 55,6 & 47,2 & 52,8 & 50 & 61,2 \\
\hline \multirow[t]{2}{*}{3} & $\mathbf{N}$ & 15 & 8 & 13 & 10 & 5 & 7 \\
\hline & $\%$ & 41,7 & 22,2 & 36,1 & 27,8 & 13,9 & 19,4 \\
\hline
\end{tabular}

\begin{tabular}{|llllllll}
\multicolumn{2}{l}{ Internato III*** } & & & & \\
\hline $\mathbf{0}$ & $\mathbf{N}$ & 0 & 0 & 0 & 0 & 1 & 0 \\
& $\%$ & 0 & 0 & 0 & 0 & 3,2 & 0 \\
\hline $\mathbf{1}$ & $\mathbf{N}$ & 3 & 10 & 5 & 9 & 14 & 6 \\
\hline $\mathbf{2}$ & $\mathbf{N}$ & 14 & 18 & 18 & 14 & 13 & 18 \\
& $\%$ & 45,2 & 58,1 & 58,1 & 45,2 & 41,9 & 58,1 \\
\hline 3 & $\mathbf{N}$ & 14 & 3 & 8 & 8 & 3 & 7 \\
& $\%$ & 45,2 & 9,7 & 25,8 & 25,8 & 9,7 & 22,6 \\
\hline
\end{tabular}

Domínio - Atividade teórica

\begin{tabular}{|c|c|c|c|c|c|}
\hline Itens & $\begin{array}{l}\text { A obriga- } \\
\text { toriedade } \\
\text { em rea- } \\
\text { lizar os } \\
\text { trabalhos } \\
\text { extraclas- } \\
\text { se }\end{array}$ & $\begin{array}{l}\text { A forma } \\
\text { adotada } \\
\text { para } \\
\text { avaliar o } \\
\text { conteúdo } \\
\text { teórico }\end{array}$ & $\begin{array}{l}\text { Sentir } \\
\text { insegu- } \\
\text { rança ou } \\
\text { medo ao } \\
\text { fazer as } \\
\text { provas } \\
\text { teóricas }\end{array}$ & $\begin{array}{l}\text { O grau de } \\
\text { dificulda- } \\
\text { de para } \\
\text { execução } \\
\text { dos tra- } \\
\text { balhos ex- } \\
\text { traclasse }\end{array}$ & $\begin{array}{l}\text { Assimilar } \\
\text { o con- } \\
\text { teúdo } \\
\text { teórico- } \\
\text {-prático } \\
\text { oferecido } \\
\text { em sala } \\
\text { de aula }\end{array}$ \\
\hline
\end{tabular}

Internato I *

\begin{tabular}{|lllllll|}
\hline $\mathbf{0}$ & $\mathbf{N}$ & 1 & 0 & 1 & 0 & 1 \\
\hline $\mathbf{1}$ & $\mathbf{N}$ & 3,4 & 0 & 3,4 & 0 & 3,4 \\
& $\%$ & 13,8 & 44,8 & 41,4 & 24,1 & 41,4 \\
\hline $\mathbf{2}$ & $\mathbf{N}$ & 11 & 12 & 13 & 18 & 11 \\
& $\%$ & 38 & 41,4 & 44,8 & 62,1 & 38 \\
\hline $\mathbf{3}$ & $\mathbf{N}$ & 13 & 4 & 3 & 4 & 5 \\
& $\%$ & 44,8 & 13,8 & 10,3 & 13,8 & 17,2 \\
\hline
\end{tabular}




\begin{tabular}{|c|c|c|c|c|c|c|}
\hline \multicolumn{7}{|c|}{ Internato $\mathrm{II}^{\star *}$} \\
\hline \multirow[t]{2}{*}{0} & $\mathbf{N}$ & 0 & 0 & 1 & 0 & 0 \\
\hline & $\%$ & 0 & 0 & 2,8 & 0 & 0 \\
\hline \multirow[t]{2}{*}{1} & $\mathbf{N}$ & 9 & 10 & 13 & 13 & 16 \\
\hline & $\%$ & 25 & 27,8 & 36,1 & 36,1 & 44,4 \\
\hline \multirow[t]{2}{*}{2} & $\mathbf{N}$ & 17 & 18 & 16 & 16 & 14 \\
\hline & $\%$ & 47,2 & 50 & 44,4 & 44,4 & 38,9 \\
\hline \multirow[t]{2}{*}{3} & $\mathbf{N}$ & 10 & 8 & 6 & 7 & 6 \\
\hline & $\%$ & 27,8 & 22,2 & 16,7 & 19,4 & 16,7 \\
\hline \multicolumn{7}{|c|}{ Internato III ${ }^{* * *}$} \\
\hline \multirow[t]{2}{*}{0} & $\mathbf{N}$ & 0 & 0 & 2 & 0 & 1 \\
\hline & $\%$ & 0 & 0 & 6,5 & 0 & 3.2 \\
\hline \multirow[t]{2}{*}{1} & $\mathbf{N}$ & 6 & 7 & 9 & 12 & 13 \\
\hline & $\%$ & 19,3 & 22,6 & 29 & 38,7 & 41,9 \\
\hline \multirow[t]{2}{*}{2} & $\mathbf{N}$ & 17 & 17 & 15 & 14 & 15 \\
\hline & $\%$ & 54,8 & 54,8 & 48,4 & 45,2 & 48,4 \\
\hline \multirow[t]{2}{*}{3} & $\mathbf{N}$ & 8 & 7 & 5 & 5 & 2 \\
\hline & $\%$ & 25,8 & 22,6 & 16,1 & 16,1 & 6,5 \\
\hline
\end{tabular}

*Valor percentual calculado considerando o número total de discentes no Internato I (29 participantes);

** Valor percentual calculado considerando o número total de discentes no Internato II (36 participantes);

*** Valor percentual calculado considerando o número total de discentes no Internato III (31 participantes).

Com relação ao domínio "Formação Profissional", verificou-se a maior representatividade, 45 (46,9\%) discentes, em "ter preocupação com o futuro profissional", sendo que o internato I apresenta a maior ocorrência, 16 (55,2\%). Por último, no domínio "Atividade Teórica", a situação referente "a obrigatoriedade em realizar os trabalhos extraclasse" foi citada por 31 (32,3\%) discentes, com o internato I em destaque, com 13 (44,8\%).

\section{DISCUSSÃO}

Há uma representação discente majoritariamente feminina, 76 (79,2\%) discentes no estudo. Esse aspecto apresenta influência histórica, pois a enfermagem foi considerada uma profissão feminina, o que ainda permanece apesar da inserção de profissionais do sexo masculino ${ }^{(10)}$ e repercute no perfil atual da profissão.

Identificou-se como faixa etária predominante 20-24 anos, dado semelhante ao encontrado em outro estudo que também discute a saúde mental entre estudantes de enfermagem, refletindo sobre exaustão emocional e despersonalização desse público ${ }^{(11)}$. O perfil etário ainda pode repercutir em incertezas frente ao futuro profissional que, somado às situações de estresse inerentes ao processo de formação, podem incitar na ideia de desistência durante o curso ${ }^{(12)}$. Os dados do estudo expressam que 54 (56,3\%) discentes já pensaram em desistir do curso.

A satisfação com a graduação, em 88 (91,7\%) discentes do estudo, está interligada com a qualidade de aprendizagem dos estudantes, podendo também ser afetada pelas características da instituição em seu contexto educacional, e pelo modo como os próprios estudantes percebem e compreendem seu ambiente de ensino ${ }^{(13)}$. Isso demonstra que a satisfação, ou não com o curso, não pode ser considerada causa imediata da intenção de desistir.

Houve prevalência dos discentes solteiros, 79 (82,4\%), e sem filhos, 84 (87,5\%), dados que podem estar relacionados com a faixa etária predominante (20 a 24 anos) no estudo. Os jovens vêm buscando independência e estabilidade financeira, procurando estabelecer uma união conjugal ao se sentirem estáveis, seguros e maduros, priorizando a conclusão de um curso universitário. Ademais, o caráter integral do curso também é algo a ser considerado ${ }^{(14)}$.

Destaca-se que 40 (41,7\%) discentes moram com amigos/colegas. A inserção do aluno no ensino superior é cercada de adaptações, as quais implicam em várias mudanças o que pode favorecer a ocorrência do estresse ${ }^{(15)}$, pois desde os semestres iniciais há maiores cobranças para o acadêmico tornar-se independente e responsável (3).

Em meio às tensões provocadas pelas novidades impostas pela vida universitária, reconhece-se a prática de atividade física importante. Contudo, nesse estudo, verificou-se uma expressividade de discentes não praticam esportes, 67 (69,8\%). A intensidade das atividades que envolvem o internato, assim como todo o curso de enfermagem, acaba por tencionar nos discentes uma concentração de energia e tempo no internato, marginalizando outras atividades importantes para o equilibrio mental e físico da vida.

Considerando a necessidade do estudante se inserir em atividades complementares que incrementam a formação universitária básica, o estudo evidencia que 67 $(69,9 \%)$ discentes não participam de grupos de estudo e pesquisa, e 39 (40,6\%) recebem algum tipo de bolsa. 
A participação dos acadêmicos em grupos de pesquisas proporciona maior aproximação com temas importantes para a formação e otimiza a capacidade de problematização, além de ampliar a visão do discente, pois instiga a investigação na pesquisa de soluções para problemas vivenciados na prática ${ }^{(16)}$. Isso incentiva a formação de um profissional diferenciado, criativo e resolutivo. Por outro lado, a diversidade de papéis assumidos pelos discentes aumenta as responsabilidades e a necessidade de lidar com potenciais estressores.

Quanto ao desenvolvimento de atividades de trabalho, 71 (74,0\%) discentes relataram que não as realizam, 70 (72,9\%) não possuem nenhuma experiência profissional na saúde e 86 (89,6\%) não apresentam outro nivel superior. Isso se associa ao fato da graduação em enfermagem ser integral, o que dificulta a realização de atividades de trabalho ${ }^{(13)}$ e até mesmo cursar outra graduação.

Sobre a ocorrência de estresse entre os discentes com a aplicação do instrumento AEEE, no domínio "Realização das atividades práticas" obteve-se prevalência na situação "ter medo de cometer erros durante a assistência ao paciente", 37 (38,5\%) discentes, sendo o internato II de maior representatividade, com 18 (50\%) discentes. Esse período caracteriza-se por vivências longas que permitem uma aproximação do interno ao serviço e à equipe. No entanto, alguns internos não se acham seguros para prestar assistência ao paciente, como evidenciado no estudo. Em diálogo, estudos apontam que os discentes ao adentrarem nos serviços vivem sentimentos de desamparo, medo e insegurança, o que pode influenciar em sua saúde e em seu processo de formação ${ }^{(17-18)}$.

No domínio "Comunicação Profissional", verificou-se maior ocorrência de estresse na situação "observação de atitudes conflitantes com outros profissionais", 21 (21,9\%), sendo mais verificado no internato II, com 9 (25\%) discentes. Os conflitos presentes no processo de comunicação profissional podem ser ocasionados pelo distanciamento entre a aplicabilidade dos conhecimentos aprendidos na universidade e as condições dos serviços de saúde, com precárias condições físicas, materiais, humanas e gerenciais ${ }^{(19)}$.

Em relação ao domínio "Gerenciamento de tempo", obteve-se a maior ocorrência de estresse, 55 (57,3\%) discentes, para a questão referente à "falta de tempo para momentos de descanso". O internato I apresenta maior expressividade nesse quesito, 20 (69,0\%). Esses resultados merecem atenção, pois a ocorrência de estresse pode interferir negativamente na saúde e no processo de ensino-aprendizagem. Outro fator influente no estresse é a busca dos estudantes pela excelência na formação que pode gerar um esgotamento da capacidade intelectual, coadunando com estudo ${ }^{(6)}$ que traz o estresse contínuo como um fator redutor de produtividade, desencadeando doenças e má qualidade de vida.

Nas situações relacionadas ao domínio "Ambiente", aquela que obteve manifestação de estresse mais acentuada foi a "distância entre a maioria dos campos de estágio e o local de moradia", 29 (30,2\%) discentes, tendo o internato I maior representatividade, com 11 (38\%). A partir desse domínio, pode-se analisar como a distância entre a faculdade, o local de moradia, de aulas práticas e os campos de estágios, além do transporte público utilizado são percebidas pelos estudantes ${ }^{(20)}$ e de que forma isso atua como estressor. Tais aspectos repercutem em uma avaliação negativa do ambiente que é contexto de vida do estudante; isso dialoga com o estudo de Bublitz e colaboradores ${ }^{(21)}$, no qual o domínio "Ambiente" foi o segundo de maior estresse para a população do estudo.

No domínio "Formação Profissional", a opção referente a "ter preocupação com o futuro profissional" obteve ocorrência acentuada nos três internatos, no entanto, o internato I destacou-se, 16 (55,2\%) discentes. O internato I configura-se como o momento de inserção do estudante de Enfermagem na prática em regime de imersão e por tempo mais prologando, e de transição, pois espera-se do estudante mais poder de tomada de decisão e condução de processos de trabalho em saúde, autonomia e responsabilidade vinculadas aos conhecimentos que devem ter sido estruturados no decorrer dos anos mais iniciais da formação.

Desse modo, o estresse gerado pelo medo quanto à inserção no mercado de trabalho e futuro profissional é resultado do sentimento de insegurança e despreparo sentido e referido por parte dos discentes para atuarem como enfermeiros. Importante refletir que identificar fatores estressores durante a graduação estimula o autocuidado do profissional ainda como acadêmico e evita que os profissionais adentrem no mercado com comprometimentos prejudiciais a sua saúde, impossibilitando, assim, a assistência de qualidade aos pacientes ${ }^{(5)}$. 
No domínio Atividade Teórica, "a obrigatoriedade em realizar os trabalhos extraclasse" representou a maior associação à ocorrência de estresse, 31 (32,3\%) discentes. Obteve maior incidência para essa situação o internato I, com 13 (44,8\%). O avançar da graduação vai incorporando estratégias de aprendizagem mais complexas e diversificadas, de modo a conseguir provocar um desempenho na formação mais próxima do ideal e retratar seu alcance de forma mais fidedigna. Um estudo (3) evidencia que a cada semestre do curso os discentes passam a desempenhar novas atividades para aprimorar habilidades e técnicas, surgindo, assim novas exigências, o que pode gerar momentos de estresse e o receio de não conciliar as atividades.

De acordo com os resultados do instrumento de AEEE, a maior frequência foi identificada na opção "sentir-se pouco estressado com as situações propostas", expressado por 36 (37,5\%) discentes. No entanto, a presença do estresse já se torna preocupante, pois sua prevalência a longo prazo pode acarretar agravos à saúde.

É necessário investir em estratégias de reconhecimento precoce das situações de estresse e de enfrentamento. Pois, ao reduzir o estresse espera-se que haja melhoras no desempenho acadêmico, na vida social e em consequência na prática profissional, visto que situações vivenciadas na universidade são similares ao campo de trabalho ${ }^{(22)}$.

\section{Limitações do estudo}

O estudo realizou uma análise do estresse em acadêmicos de enfermagem que se encontravam nos três internatos acadêmicos de um curso de graduação. Consequentemente, é preciso ter cautela na generalização dos resultados para todo o período da graduação em enfermagem e em outras realidades de formação. Os resultados sugerem a necessidade de mais aprofundamento para melhor lidar com o estresse e seus fatores desencadeantes, especialmente considerando sua mutabilidade ao envolver atores sociais, inscritos na história.

\section{Contribuição do estudo para a prática}

O estudo desperta para ocorrência de estresse entre discentes de Enfermagem e como isso pode repercutir no adoecimento mental crônico do enfermeiro desde a formação universitária. Na prática clínica, tem-se uma acentuação do esgotamento profissional, pois essa sensação é anterior à inserção no mercado de trabalho. Projetivamente, os futuros enfermeiros estarão mais vulneráveis às complexidades do processo de trabalho, podendo levar a uma prática apática, pouco inovadora em razão do esgotamento mental, menos reflexiva e mais sujeita a erros.

\section{CONCLUSÃO}

A pesquisa permitiu traçar um perfil sociodemográfico e acadêmico dos estudantes. Estes são de prevalência feminina, solteira, de faixa etária de 20 a 24 anos, sem filhos. Além disso, residem com a família, não praticam atividades físicas, mas realizam atividades de lazer. Quanto ao perfil acadêmico, identificou-se o destaque à satisfação com o ensino superior, apesar de já terem pensado em desistir do curso. A maioria não participa de grupos de estudo, não trabalha, não tem experiência profissional na saúde e não possui nível superior em outra área. Houve predomínio de discentes que não recebem auxílio financeiro.

Sobre o nivel de estresse, prevaleceu o "sentir-se pouco estressado com as situações propostas". No entanto, a simples presença do estresse no cotidiano acadêmico já consiste em um dado preocupante, pois pode-se inferir a possibilidade da continuidade ou agravamento do mesmo no exercício da profissão, ou ainda na vida acadêmica. $\mathrm{Na}$ enfermagem, essa intensidade ganha proporção maior por se tratar de uma profissão que, além de envolver o cuidado direto a pessoas com saúde debilitada, também abrange um processo de trabalho que pode acarretar desgaste físico e psicológico

Assim, o estudo contribui com subsídios para a revisão de metodologias de ensino e a realização de intervenções adequadas que visem ao bem-estar acadêmico com o intuito de proporcionar aos discentes maior satisfação no curso e, consequentemente, melhores perspectivas sobre a profissão no seu ingresso no mundo do trabalho.

\section{Contribuição dos autores}

MCCB - concepção, análise e interpretação dos dados, redação do artigo, revisão crítica e revisão final; RMBVA - concepção, análise e interpretação dos dados, e redação do artigo; MASD - análise dos dados, revisão crítica e revisão final; LCCS - análise dos dados, revisão crítica e revisão final; PVR - análise dos dados e revisão final; MPM - análise dos dados e revisão final. 


\section{REFERÊNCIAS}

1. Cardoso AWM, Bekke HA. Estresse ocupacional em profissionais de saúde dos centros de atenção psicossocial. Rebrast [Internet]. 2018 [cited 2019 Jul 12];1(1):23-9. Available from: http://periodicos.ifpb.edu.br/index.php/rebrast/article/view/1552.

2. Instituto Nacional de Estudos e Pesquisas Educacionais Anísio Teixeira. Sinopses Estatísticas da Educação Superior do ano 2017. Inep [Internet]. 2018 [cited 2018 Dez 7]. Available from: http://portal.inep.gov.br/superior-censosuperior-sinopse.

3. Cestari VRF, Barbosa IV, Florêncio RS, Pessoa VLMP, Moreira MM. Estresse em estudantes de enfermagem: estudo sobre vulnerabilidades sociodemográficas e acadêmicas. Acta Paul. Enferm [Internet]. 2017 [cited 2019 Jul 11];30(2):190-6. Available from: http://www.scielo.br/pdf/ape/v30n2/19820194-ape-30-02-0190.pdf.

4. Vanzuita A, Pereira A, Zluhan MR, Raitz TR. Uma discussão sobre trajetórias escolares na atualidade: do ensino médio ao ensino superior. Rev. Espacios [Internet]. 2016 [cited 2019 Jul 12];37(33):1-6. Available from: http:// www.revistaespacios.com/al6v37n33/16373301.html.

5. Rodrigues HC, Dias MAS, Aragão AEA, Silva MAM, Gomes DF, Brito MCC. Internato de enfermagem na atenção básica: desafios da sua efetividade. Rev. enferm. UERJ [Internet]. 2018 [cited 2019 Jul 11];26:1-6. Available from: https://www.e-publicacoes.uerj.br/index.php/enfermagemuerj/article/ view/26979/28193

6. Santos KF, Ferreira VT, Silva PR, Vilella DV. Aplicabilidade do inventário de Beck nos acadêmicos de enfermagem em uma instituição de ensino de Minas Gerais. Enferm. Foco [Internet]. 2018 [cited 2019 Jul 12];9(3):81-8. Available from: http://revista.cofen.gov.br/index.php/enfermagem/article/ view/1214/466

7. Chaves LB, Souza TB, Silva MVC, Oliveira CFO, Lipp MEN, Pinto ML. Estresse em universitários: análise sanguínea e qualidade de vida. Rev. bras. ter. cogn [Internet]. 2016[cited 2018 Dez 7];12(1):20-6. Available from: http://pepsic.bvsalud.org/scielo.php?script=sci_abstractEpi$d=S 1808-56872016000100004$ \&lng=ptEnrm=iso.

8. Bublitz S. Estresse em Discentes de Enfermagem de Quatro Instituições Brasileiras. [Dissertação]. Santa Maria: Universidade Federal de Santa Maria; 2014

9. Costa ALS, Polak C. Construção e validação de instrumento para avaliação de estresse em estudantes de enfermagem (AEEE). Rev. Esc. Enferm. USP [Internet]. 2009 [cited 2019 Dez 7];43:1017-26. Available from: http://www. scielo.br/scielo.php?script=sci_arttextEpid=\$0080-62342009000500005

10. Queiroz DL, Souza JC. Qualidade de vida e capacidade para o trabalho de profissionais de enfermagem. Psicol. inF. [Internet]. 2012 [cited 2018 Jun 21];16(16):103-26. Available from: http://pepsic.bvsalud.org/pdf/psicoinfo/ v16nl6/v16nl6a05.pdf

11. Martins C, Campos S, Duarte J, Martins R, Moreira T, Chaves C. Situações indutoras de stress e Burnout em estudantes de enfermagem nos ensaios clínicos. Rev. port. enferm. saúde mental [Internet]. 2017 [cited 2018 Jun 21];5:25-32. Available from: http://www.scielo.mec.pt/pdf/rpesm/nspe5/ nspe5a05.pdf

12. Bublitz S, Guido LA, Lopes LFD, Freitas EO. Associação entre estresse e caracteristicas sociodemográficas e acadêmicas de estudantes de enfermagem. Texto \& contexto enferm. [Internet] 2016. [cited 2019 Jul 13];25(4):1-
7. Available from: http://www.scielo.br/pdf/tce/v25n4/pt_0104-0707-tce-25-04-2440015.pdf

13. Ramos SM, Barlem JGT, Lunardi VL, Barlem ELD, Silveira RS, Bordignon SS. Satisfação com a experiência acadêmica entre estudantes de graduação em enfermagem. Texto \& contexto enferm. [Internet] 2015 [cited 2018 Jun 21];24(1):187-95. Available from: http://www.scielo.br/pdf/ tce/v24nl/pt_0104-0707-tce-24-01-00187.pdf

14. Ximenes Neto FRG, Muniz CFF, Dias LJLF, Diogenes Júnior F, Silva MAM, Oliveira EM. Perfil sociodemográfico dos estudantes de enfermagem da Universidade Estadual Vale do Acaraú (UVA). Enferm. Foco [Internet]. 2017 [cited $2019 \mathrm{Jul}$ 13];8(3):75-9. Available from: http://revista. cofen.gov.br/index.php/enfermagem/article/view/1532/404

15. Soares AB, Del Prette ZAP. Habilidades sociais e adaptação à universidade: Convergências e divergências dos construtos. Anál. psicol[Internet] 2015 [cited 2018 Jun 21];2(33):139-51. Available from: http://www.scielo. mec.pt/scielo.php?script=sci_arttext\&pid=\$0870-82312015000200001

16. Azevedo IC, Silva RCL, Carvalho DPRP, Cruz GKP, Lima JVH, Ferreira Júnior MA. Importância do grupo de pesquisa na formação do estudante de enfermagem. Rev. enferm. UFSM [Internet]. 2018 [cited 2019 Jul 13]:8(2):390-8. Available from: https://periodicos.ufsm.br/reufsm/article/ view/26003/pdf

17. Dias EP, Stutz BL, Resende TC, Batista NB, Sene SS. Expectativas de alunos de enfermagem frente ao primeiro estágio em instituições de saúde. Psicopedagogia [Internet]. 2014 [cited 2018 Jun 21];31(94):44-55. Available from: http://pepsic.bvsalud.org/pdf/psicoped/v3ln94/06.pdf

18. Restelatto MTR, Dallacosta FM. Vivências do acadêmico de enfermagem durante o estágio com supervisão indireta. Enferm. Foco [Internet] 2018 [cited 2019 Jul 13];9(4):34-8. Available from: http://revista.cofen.gov. br/index.php/enfermagem/article/view/1156/474

19. Renno HMS, Brito MJM, Ramos FRS. O estágio curricular e o sofrimento moral do estudante de enfermagem. Enferm. Foco [Internet]. 2015 [cited 2018 Jun 21];6(1/4):51-5. Available from: http://revista.cofen.gov.br/ index.php/enfermagem/article/view/577

20. Oliveira HFR, Risso HRF, Vieira FSF, Leal KASL, Noda DKG, Martins GC. Estresse e qualidade de vida de estudantes universitários. Revista CPAOV [Internet]. 2015 [cited 2018 Jun 21]:7(2):2-8. Available from: http:// www.cpaqv.org/revista/CPAQV/ojs-2.3.7/index.php?journal=CPAOV\&page=articleEop=viewधpath\%5B\%5D=77

21. Bublitz S, Freitas EO, Kirchhof RS, Lopes LFD, Guido LA. Estressores entre Acadêmicos de Enfermagem de uma Universidade Pública. Rev. enferm. UERJ [Internet]. 2012 [cited 2018 Dez 7];20(2):739-45. Available from: https://www.e-publicacoes.uerj.br/index.php/enfermagemuerj/article/view/5992/4301

22. Bublitz S, Guido LA, Lopes LFD, Freitas EO. Associação entre estresse e caracteristicas sociodemográficas e acadêmicas de estudantes de enfermagem. Texto \& Contexto Enferm [Internet]. 2016 [cited 2018 Jun 21];25(4):1-7. Available from: http://www.scielo.br/pdf/tce/v25n4/pt_ 0104-0707-tce-25-04-2440015.pdf

RECEBIDO: 16/06/2019

ACEITO: 09/10/2019 